\title{
Ongoing decline of suitable habitat for the Critically Endangered Gurney's pitta Hydrornis gurneyi
}

\author{
Tommaso Savini, Nay Mro Shwe and Niti Sukumal
}

\begin{abstract}
From 1999 onwards, level, lowland forests (altitude $<150 \mathrm{~m}$, slopes $<10^{\circ}$ ) in the Tanintharyi Region of southern Myanmar have been cleared on a large scale and replaced by oil palm plantations. This has resulted in a drastic decline in suitable habitat for several species, including Gurney's pitta Hydrornis gurneyi (Passeriformes, Pittidae). The habitat for this species has decreased by $>80 \%$, leading to its categorization as Critically Endangered on the IUCN Red List in 2019. As threats in the region have continued, we updated information on the status of the species' habitat in January 2020, and examined forest loss in the three strongholds where the species still persists in the wild. Since the previous estimate in 2017 , suitable habitat in these locations has decreased by $8 \%$ (from 656 to $603 \mathrm{~km}^{2}$ ), with $>10 \%$ of the remaining area now in fragments of $<_{1} \mathrm{~km}^{2}$, which are unsuitable for the mid- to long-term survival of the species. Forest degradation and edge effects from increased fragmentation have led to further loss of suitable habitat in these strongholds. Projections indicate that unless conservation action is taken, all suitable habitat will disappear by 2080 . The main threat to the long-term survival of Gurney's pitta is the lack of legal protection of primary lowland forests, resulting in uncontrolled clearance for smalland large-scale agriculture and industrial development. We provide recommendations to reduce the rate of loss of the remaining suitable habitat for the species.
\end{abstract}

Keywords Forest loss, Gurney's pitta, hotspot, Hydrornis gurneyi, land clearing, lowland forest, oil palm plantation, Tanintharyi

\section{Introduction}

Couth-east Asian biodiversity is collapsing (Sodhi et al., $\mathrm{S}_{2004}$ ) as a consequence of habitat degradation and loss, mostly because of large-scale clearance for agriculture and infrastructure development (Laurence et al., 2014; Laurance \& Arrea, 2017). Primary forest in the lowlands of South-east

Tommaso SAVINI Conservation Ecology Program, King Mongkut's University of Technology Thonburi, Bangkok, Thailand

NAY Myo SHwE (@o orcid.org/0000-0003-3739-3955) Fauna \& Flora International, Cambridge, UK

Niti SuKUmal (Corresponding author, (1) orcid.org/0000-0002-7758-621X) Conservation Ecology Program, King Mongkut's University of Technology Thonburi, 49 Soi Thian Thale 25, Bang Khun Thian Chai Thale Road, Bangkok 10150, Thailand. E-mail niti_230@hotmail.com

Received 4 June 2020. Revision requested 6 August 2020.

Accepted 15 October 2020. First published online 15 July 2021.
Asia, extending from the plains to the foothills (Wells, 1976), has declined by $>50 \%$ over the past 20 years (Namkhan et al., 2021). This raises concern for threatened lowland forest biodiversity (Aratrakorn et al., 2006), particularly in the unique and relatively pristine lowland forest transition zone surrounding the Isthmus of Kra, where Sundaic and Indochinese faunas meet (Hughes et al., 2003).

The region supports several threatened species, including the Critically Endangered helmeted hornbill Buceros vigil and Sunda pangolin Manis javanica, the Endangered whitehanded gibbon Hylobates lar, Malayan tapir Tapirus indicus, Indochinese tiger Panthera tigris and dhole Cuon alpinus, and the Vulnerable large green pigeon Treron capellei. Gurney's pitta Hydrornis gurneyi (Passeriformes, Pittidae) is endemic to this transition zone and its habitat has decreased by $>80 \%$ during $1999-2017$ as a consequence of large-scale oil palm expansion, small-scale betel nut cultivation, and infrastructure development (Shwe et al., 2020). This substantial habitat loss, combined with the fact that the species is considered functionally extinct in neighbouring Thailand (Round, 2014), led to its recategorization as Critically Endangered on the IUCN Red List in 2019 (BirdLife International, 2019). The threat status had previously been lowered to Endangered in 2008, after the discovery of what was thought to be a large population in southern Myanmar, although the continuing threats to the species' habitat were acknowledged (Donald et al., 2009). The reassessment as Critically Endangered is justified by a drastic population decline resulting from ongoing deforestation throughout the species' remaining range. A major concern is that none of the remaining core habitat is currently protected, and it is uncertain whether it will be in the future (BirdLife International, 2019). The threats to the species are thus expected to continue or increase as a result of rapid economic growth following Myanmar's return to democracy in 2011 (Donald et al., 2015; BirdLife International, 2019).

Here, we aimed to update information on the status of remaining Gurney's pitta habitat and document any change since the previous estimate in 2017 (Shwe et al., 2020), investigate the status of the three remaining strongholds (Shwe et al., 2020) with particular focus on forest patches $>20 \mathrm{~km}^{2}$, and predict future change in lowland forest habitat in the absence of effective intervention.

\section{Study area}

This study covers the entire remaining range of Gurney's pitta in the Tanintharyi Region (Hume, 1875), southern 

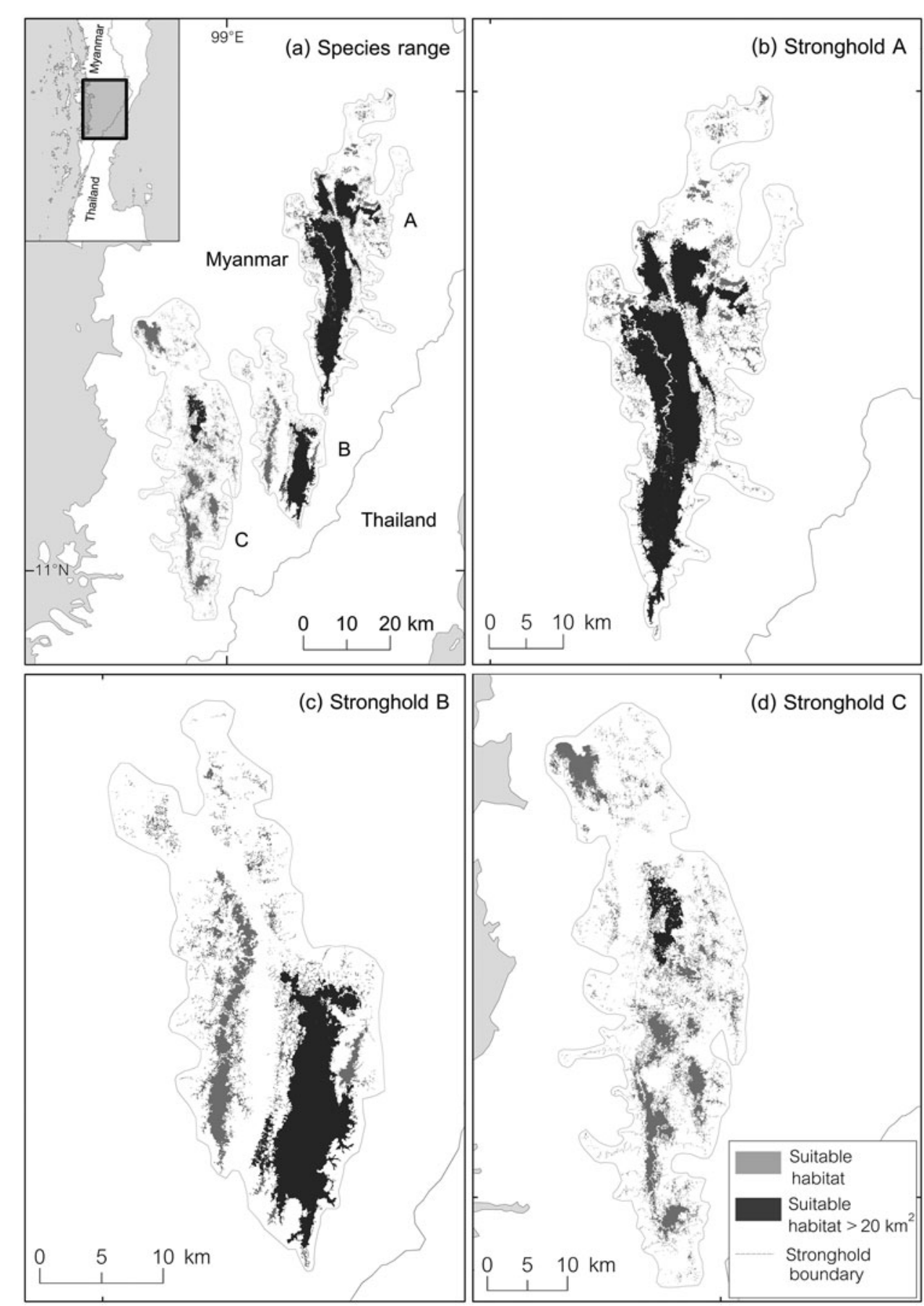

Dechie OT Tailatior Gurney s pilta

(1)
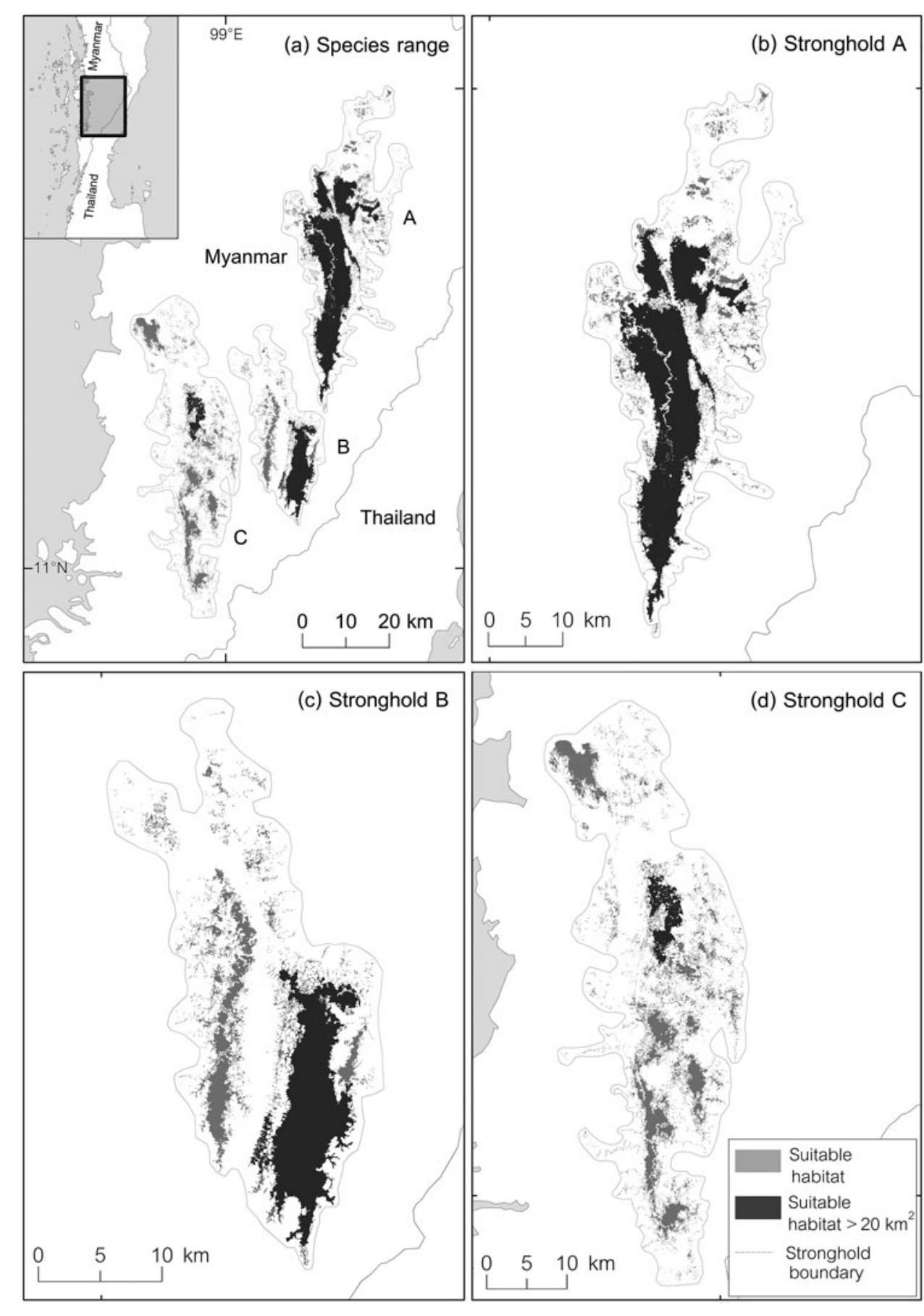

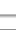

FIG. 1 (a) Remaining lowland closed canopy forest cover in the range of Gurney's pitta Hydrornis gurneyi (grey) in Tanintharyi and remaining patches larger than $20 \mathrm{~km}^{2}$ (black), as of January 2020. (b-d) Details of the suitable habitat cover in Strongholds A, B and C, respectively.
Myanmar (Donald et al., 2014; Fig. 1a), at an altitude of 19-672 $\mathrm{m}$. There is a dry season (November-March), with a monthly rainfall of $<100 \mathrm{~mm}$, and a wet season (April-October), with a mean monthly rainfall of $750 \mathrm{~mm}$ (Baskett, 2015). The area was originally covered by evergreen forest, but the natural vegetation has been degraded since 1999 by extensive conversion to oil palm plantation and small-scale agriculture (Shwe et al., 2020).

\section{Methods}

Suitable habitat in 2020 We defined closed-canopy forest and degraded primary forest with bamboo at $<150 \mathrm{~m}$ altitude and on slopes $<10^{\circ}$ as habitat suitable for Gurney's pitta (Shwe et al., 2020). We obtained slope and altitude data from ASTER Global Digital Elevation Map (30 m resolution; Abrams et al., 2020) and defined the extent of suitable habitat using the reclassify toolbox in ArcGIS 10.3 (Esri, 
Redlands, USA). We identified suitable forest cover for 2020 from Landsat 8 Enhanced Thematic Mapper satellite images (30 m resolution), derived from EarthExplorer (USGS, 2020). We categorized land cover as forest and non-forest, with only forest areas considered suitable for Gurney's pitta, and assessed recent forest decline by comparing forest cover in January 2020 with that from 2017 (Shwe et al., 2020).

Strongholds of remaining habitat We assessed the suitable habitat in each of the three remaining strongholds (Shwe et al., 2020) using the forest cover map from January 2020. When rediscovered in southern Thailand in 1986, the species inhabited a c. $30 \mathrm{~km}^{2}$ lowland forest patch fragmented by clearings and rubber plantations (Round, 2014). However, as patches of suitable habitat $>30 \mathrm{~km}^{2}$ are limited in the Tanintharyi Region, the stronghold was defined as a forested area including only habitat patches $>20 \mathrm{~km}^{2}$, each of which may hold a population of 140-200 pairs, according to preliminary distance sampling data from an ongoing large-scale survey (NMS, unpubl. data). We removed all forest fragments $<1 \mathrm{~km}^{2}$ from the analysis, as these are unlikely to sustain viable populations in the long term.

Hotspots of forest loss We investigated spatio-temporal trends in forest loss throughout the known range of Gurney's pitta using the Emerging Hot Spot Analysis tool in ArcGIS (Harris et al. 2017). The tool first conducts a hotspot analysis using the Getis-Ord Gi statistic (Ord \& Getis, 1995) to identify statistically significant spatial clustering patterns. Once spatial clustering patterns (so-called hot and cold spots) are identified, the tool evaluates temporal changes in the patterns using a Mann-Kendall test (Mann, 1945; Kendall \& Gibbons, 1990) to determine whether deforestation rates are constant, increasing or decreasing over time. For our analysis, we used raster data of annual forest loss during 2000-2018, with a resolution of $30 \mathrm{~m}$ (Hansen et al., 2013) and limited to the extant habitat of Gurney's pitta in 1999 (Shwe et al., 2020). Prior to our analysis, we converted the annual forest loss data to a netCDF (network common data form) space-time cube using the Create Space Time Cube tool in ArcGIS, to aggregate forest loss events within space-time bins. The tool tallies the number of forest loss events within each hexagonal bin, defined here with a spatial and temporal resolution of $250 \mathrm{~m}$ (the width of each 5.4 ha hexagon) and 1 year, respectively. The Emerging Hot Spot Analysis tool then compares the number of forest loss events within each bin to those within a predefined neighbourhood distance (in our case $2.5 \mathrm{~km}$ ) and the global average to calculate relevant statistics. By default, the Emerging Hot Spot Analysis tool categorizes each bin into one of 17 distinct spatio-temporal categories (one category for bins with no significant deviation from the neighbouring areas/global average, plus eight hotspot and eight cold spot categories; Esri, 2016). We focused our analysis on the hotspots, which we aggregated into two categories to determine the risk of future forest loss: new hotspots with significant, recent forest loss (i.e. areas that became statistically significant hotspots after 2017), and other hotspots (i.e. all hotspot areas not categorized as new) where forest loss was either consistent over a longer period or sporadic (scattered in time and isolated in space). We then overlaid these hotspots on a map of the remaining strongholds of Gurney's pitta habitat, to identify hotspots of forest loss within each stronghold.

Estimating future habitat decline We predicted the spatial distribution of future forest loss using a Bayesian linear model. We assumed a constant rate of forest loss (the historical loss rate) and determined the fate of 47 suitable habitat patches $>20 \mathrm{~km}^{2}$ using data from 1999, 2003, 2012, 2017 and 2020. The prior model parameters were set with a normal distribution of intercept and coefficients, and an exponential distribution of standard deviation. We defined the year as a predictor variable, to predict a response variable, the logarithm of the area of suitable habitat patches $>20 \mathrm{~km}^{2}$ each year. We set 4,000 as the posterior sample size to express the plausible range of posterior distribution results. We conducted the analysis using the packages rstanarm and rstan (McElreath, 2019) in R 4.0.2 (R Development Core Team, 2014).

\section{Results}

Suitable habitat in 2020 In January 2020, lowland forest cover was $603 \mathrm{~km}^{2}$ in the three strongholds, a reduction of c. $8 \%$ compared to 2017 (Fig. 2a). When all unsuitable fragments $<_{1} \mathrm{~km}^{2}$ were removed, the remaining suitable habitat covered $476 \mathrm{~km}^{2}$, of which $63 \%\left(378 \mathrm{~km}^{2}\right)$ was in five larger patches $>20 \mathrm{~km}^{2}$ (Fig. 1a).

Strongholds of remaining habitat Stronghold A accounted for $330 \mathrm{~km}^{2}$ (c. $55 \%$ ) of the total suitable habitat cover. When unsuitable fragments were removed, the remaining suitable habitat was $283 \mathrm{~km}^{2}$, with three patches $>20 \mathrm{~km}^{2}$ covering $277 \mathrm{~km}^{2}$ (Fig. 1b). Stronghold B encompassed $121 \mathrm{~km}^{2}(20 \%$ of the total remaining cover), which was reduced to $100 \mathrm{~km}^{2}$ when unsuitable fragments were removed. There was only one patch $>20 \mathrm{~km}^{2}$, covering $78 \mathrm{~km}^{2}$ (Fig. 1c). Stronghold $\mathrm{C}$ appeared to be the most degraded, with $152 \mathrm{~km}^{2}$ of suitable habitat (25\%), reduced to $93 \mathrm{~km}^{2}$ after unsuitable fragments were removed, and only one large patch, of $23 \mathrm{~km}^{2}$ (Fig. 1d).

Hotspots of forest loss As of January 2020, the suitable habitat for Gurney's pitta was reduced by $82 \%$ compared 

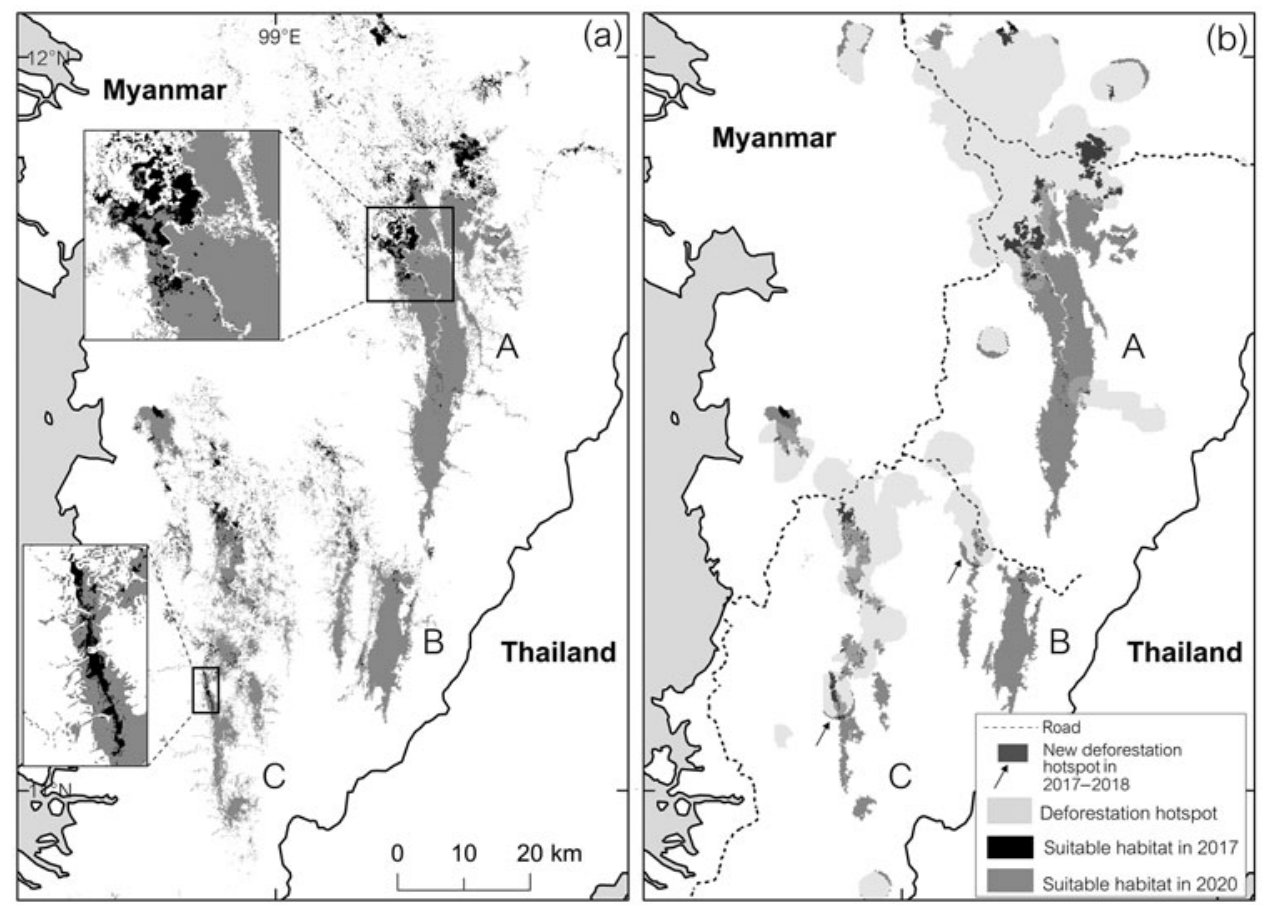

FIG. 2 (a) Changes in forest cover during mid 2017-January 2020 , with black areas indicating forest loss in the 2.5-year period. (b) Deforestation hotspots, identified between 2000 and 2018 , overlaid on the forest cover remaining in January 2020, excluding fragments $<1 \mathrm{~km}^{2}$.

to the estimated $3,395 \mathrm{~km}^{2}$ of habitat available before expansion of oil palm plantations began in 1999 (Shwe et al., 2020). Over $80 \%$ of the areas where forest was lost during 2017-2020 overlapped with deforestation hotspots. The only habitat patch $>20 \mathrm{~km}^{2}$ in stronghold $\mathrm{C}$ is of particular concern as it overlapped entirely with deforestation hotspot areas (Fig. 2b).

Estimating future habitat decline Because only 5 years of data were available for analysis, there was uncertainty in

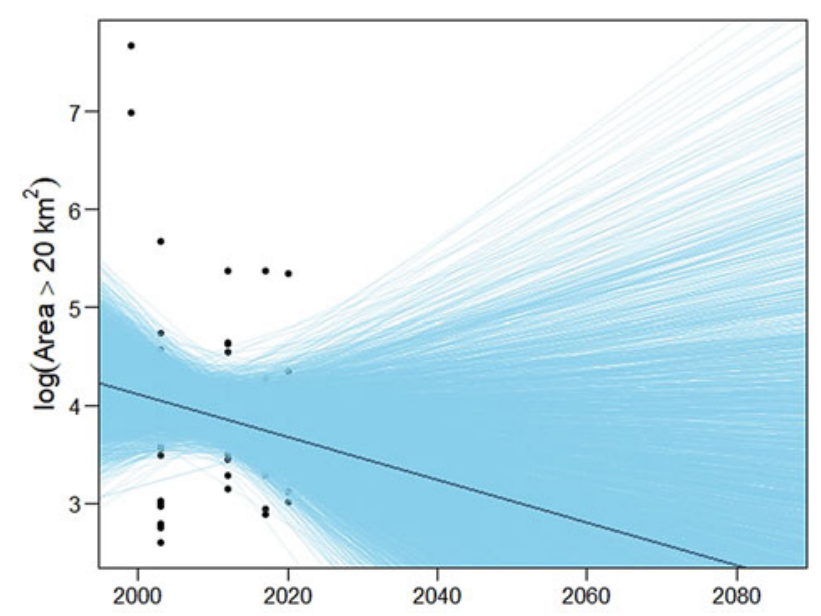

Fig. 3 Observed and future predicted changes in suitable habitat coverage (for patches $>20 \mathrm{~km}^{2}$ ) from 1999 to 2080 . Black dots represent the 47 suitable habitat patches observed in 1999, 2003, 2012, 2017 and 2020. Blue lines represent the uncertainty range of the prediction, and the black line is the median trend of the prediction. the prediction of potential sizes of suitable habitat patches, with a wide range of posterior distribution values (Fig. 3). However, $81 \%$ of posterior distribution results showed a negative trend, and the median trend (Fig. 3) showed a decrease in forest area. If no conservation action is taken and the rate of decrease continues, no habitat patches $>20 \mathrm{~km}^{2}$ will remain by 2080 .

\section{Discussion}

Forest loss and degradation are the most urgent threats to the conservation of Gurney's pitta (Bhagwat et al., 2017). Forest loss in Myanmar has been largely linked to agricultural expansion and infrastructure development (Lim et al., 2017). This has particularly affected the lowlands of the Tanintharyi Region in southern Myanmar, where forest cover declined by 80\% during 1999-2017 (Shwe et al., 2020), largely because of the expansion of large-scale oil palm plantations (Saxon \& Sheppard, 2014). A moratorium on new plantations (FFI, 2016) was relaxed in 2016 following an order from the regional government. Expansion of smalland large-scale orchards and betel nut plantations have also contributed to forest loss (Shwe et al., 2020), as has road construction. Forest loss recorded during 2017-2020 has exacerbated edge effects and habitat fragmentation, with many patches now too small to guarantee the longterm survival of Gurney's pitta (Fig. 2a,b). Our analysis predicts a nearly complete loss of all lowland forest by 2080 .

Strongholds A and B are currently the most viable patches for the species' long-term survival, but are subject to degradation and fragmentation because of ongoing 

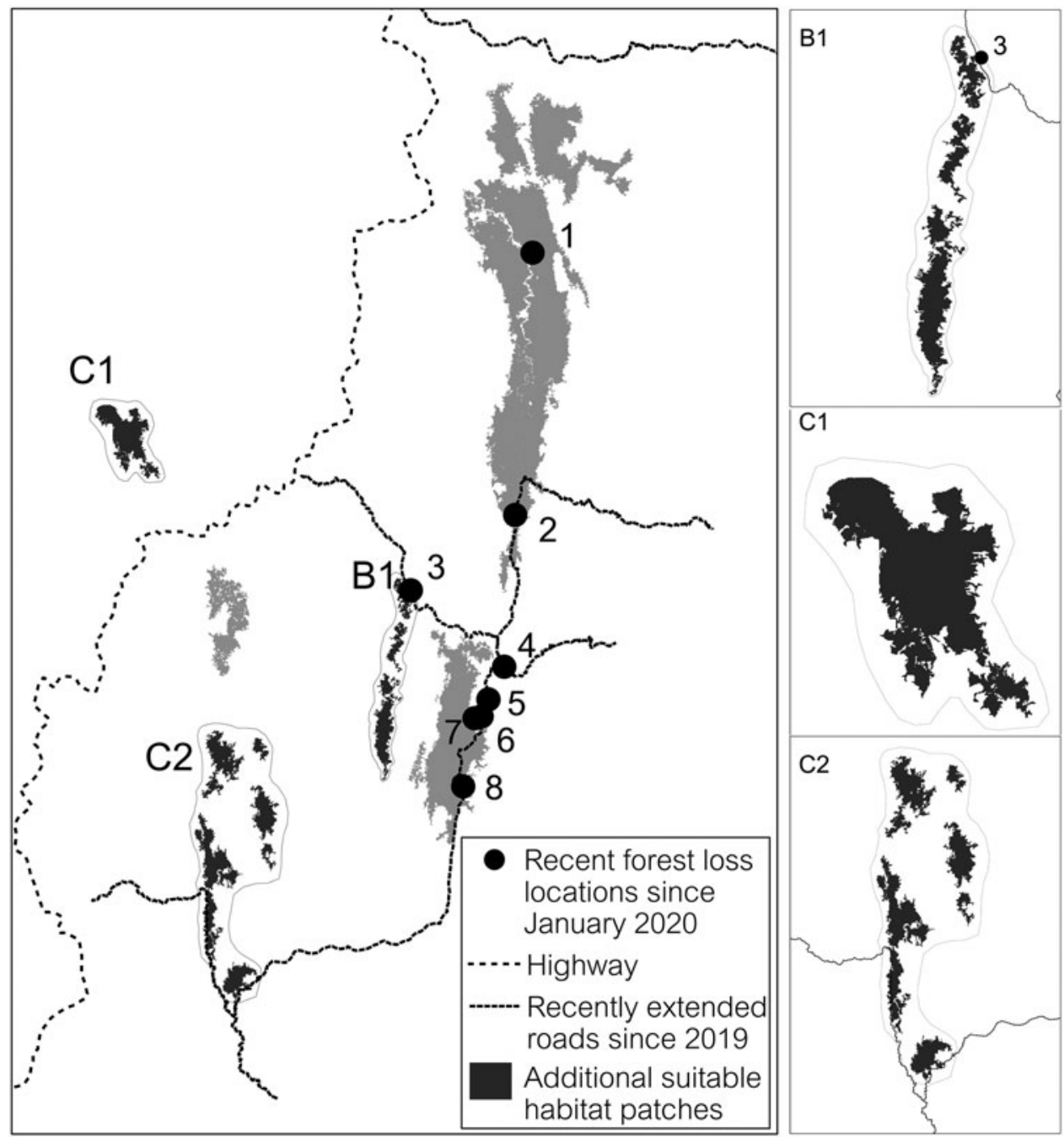

FIG. 4 Ongoing threats to remaining suitable habitat of Gurney's pitta (since February 2020). Dots indicate sites with different threats recorded: (1) limestone mining for cement manufacturing inside NgaWun Reserved Forest, (2-5) land clearance for small-scale cultivation, directly affecting well-known birdwatching sites where the species was reported, particularly in the Phayatan area in stronghold $\mathrm{B}$, (6) guano extraction for industrial purposes, (7) development of a new major Buddhist temple, and (8) first recorded landmine incident. The detailed maps of $\mathrm{B}_{1}, \mathrm{C} 1$ and $\mathrm{C}_{2}$ show possible ways to obtain suitable habitat patches $>20 \mathrm{~km}^{2}$ by linking small areas at low altitude and with gentle slopes, to enable movement of birds between patches (Donald et al., 2014).

disturbances recorded since January 2020 (Fig. 4). Stronghold $\mathrm{C}$ is the most degraded, with only one patch $>20 \mathrm{~km}^{2}$ (Fig. 1C). As this stronghold lies within a deforestation hotspot and is isolated from the other two strongholds, it is questionable whether the Gurney's pitta population there is still viable, although the area receives some protection through community-based assessment and mitigation of threats (including snare removal) because of the presence of the tiger Panthera tigris, a conservation priority species. Strongholds B and C could potentially be expanded by connecting nearby smaller suitable habitat patches $\left(<20 \mathrm{~km}^{2}\right)$ separated by forested hills up to $250 \mathrm{~m}$ altitude on rugged terrain, where the species has been reported sporadically (Donald et al., 2014; Fig. 4a). Stronghold $\mathrm{B}$ could be enlarged by $19 \mathrm{~km}^{2}$ by connecting three small neighbouring patches (Fig. 4b). Similarly, stronghold C could be expanded by $20 \mathrm{~km}^{2}$ and $48 \mathrm{~km}^{2}$ through the addition of two new patches (Fig. 4c,d).

In all three strongholds, road expansion is intensifying the threats to Gurney's pitta (Fig. 2b). Most of the ongoing construction involves upgrading old logging roads as the regional government strives to develop the local economy through increased trans-border trade with Thailand. This could exacerbate existing threats: there have been reports of increased illegal cross-border trade in forest products and sporadic trade in Gurney's pittas for the pet market (Gurney's Pitta Working Group, 2017). Road expansion also facilitates the further incursion of deforestation into Tanintharyi from Thailand (Donald et al., 2015).

Loss of suitable habitat, facilitated by lack of enforcement and appropriate protection, was the principal cause of the functional extinction of Gurney's pitta in Thailand. After the rediscovery of the species in 1986 (Round \& Treesucon, 1986), protected areas were established with the aim to preserve what was at that time the only known population. However, the economically valuable flat lowland forest that the species requires were systematically excluded from these protected areas (Round, 2014). The situation in southern Myanmar is similar, and several attempts to secure legal protection for the remaining lowland forest have been unsuccessful. The proposed Lenya National Park, including Lenya Reserve Forest and Lenya Reserve Forest Extension, 
would have covered most of the remaining strongholds (Donald et al., 2015). However, in June 2019 the proposal, first suggested in October 2004, was dropped because of problems in conducting reliable land and boundary surveys, and an uncertain political situation. The implementation of protection strategies such as patrolling is hampered by the emerging threat of landmines. The first recorded incident involving an exploding landmine, by which a villager was injured, occurred in April 2020 (site 8, Fig. 4); it is unknown who placed the mine(s) and for what purpose.

A new opportunity for protecting lowland forest has arisen in 2019 under the Conservation of Biodiversity and Protected Areas Law, amended in May 2019, with the approval of proposals by local communities to implement Community Conserved Areas or Indigenous Community Conserved Areas. Both designations facilitate a role for Indigenous communities in establishing and managing newly formed protected areas, supporting a bottom-up approach rather than a top-down system. This permits the recruitment of park wardens (or park chiefs) from local communities, who will lease the area for 30 years from the Myanmar Forest Department. This approach would not only allow local communities to manage protected areas following traditional, sustainable practices but, by sharing decision-making power in resource management, would also prevent some of the problems that caused the rejection of the proposal to establish Lenya National Park. Stakeholders are advocating for detailed provisions describing how such Conserved Areas could be implemented and explicitly codified within Myanmar's Land Law reform process. Fauna and Flora International (FFI) Myanmar has been working with forest dwellers and hunters to offer alternative livelihood opportunities such as motorbike repair and tailoring.

Data to estimate the current status of Gurney's pitta populations will be provided by ongoing surveys that are carried out by FFI, Myeik University and members of village conservation groups. These surveys focus on a variety of wildlife and will continue until the end of 2021. In addition to providing a reliable Gurney's pitta population status estimate in each stronghold, the surveys will document new land clearing and encroachment of small-scale farms. In collaboration with FFI, communities are actively participating in campaigns to remove snares and driftnets used to catch terrestrial wildlife, which is raising community interest in biodiversity conservation. Such activities should be expanded as the Forest Department lacks sufficient staffing and budget to adequately patrol Gurney's pitta strongholds. To conserve the remaining habitat and threatened species such as Gurney's pitta, more collaboration among communities, civil society, and government institutions needs to be fostered.

In the longer term, attempts need to be made to establish the proposed Lenya National Park. This will require close collaboration with the regional government, to help resolve the management conflict between the Forest Department and local communities. Gurney's pitta could also be adopted as a flagship species, designated as the Tanintharyi regional bird, and used to promote ecotourism opportunities.

Acknowledgements We thank Matthew Granger for help with the analysis of the long-term decline of suitable habitat; Maliwan Namkhan for assistance with the update of the 2020 forest cover map; Parinya Padungtin for providing information on locations of forest loss in stronghold A; Matthew Grainger, Philip D. Round and two anonymous reviewers for their critiques; and Oscar Nnaemeka and Greg Irving with language editing. This research received no specific grant from any funding agency, or commercial or not-for-profit sectors.

Author contributions Study design, data collection and analysis, writing: all authors.

\section{Conflicts of interest None.}

Ethical standards This research abided by the Oryx guidelines on ethical standards and did not involve human subjects, experimentation with animals and/or collection of specimens.

\section{References}

Abrams, M., Crippen, R. \& Fujisada, H. (2020) Aster Global Digital Elevation Model (GDEM) and ASTER Global Water Body Dataset (ASTWBD). Remote Sensing, 12, 10.339o/rs12071156.

Aratrakorn, S., Thunhikorn, S. \& Donald, P.F. (2006) Changes in bird communities following conversion of lowland forest to oil palm and rubber plantations in southern Thailand.

Bird Conservation International, 16, 71-82.

B Asket t, J.P.C. (2015) Myanmar Oil Palm Plantations: A Productivity and Sustainability Review. Fauna \& Flora International, Yangon, Myanmar.

Bhagwat, T., Hess, A., Horning, N., Khaing, T., Thein, Z.M., AUnG, K.M. et al. (2017) Losing a jewel: rapid declines in Myanmar's intact forests from 2002-2014. PLOS ONE, 12, e0176364.

Birdifie International (2019) Hydrornis gurneyi. In The IUCN Red List of Threatened Species 2019: e.T22698628A157110021. dx.doi. org/10.2305/IUCN.UK.2019-3.RLTS.T22698628A157110021.en [accessed 14 February 2020].

Donald, P.F., Aratrakorn, S., Htun, T.W., Eames, J.C., Hla, H., Thunhikorn, S. et al. (2009) Population, distribution, habitat use and breeding of Gurney's pitta Pitta gurneyi in Myanmar and Thailand. Bird Conservation International, 19, 353-366.

Donald, P.F., Hla, H., Win, L., Aung, T.D., Moses, S., Zaw, S.M. et al. (2014) The distribution and conservation of Gurney's pitta Pitta gurneyi in Myanmar. Bird Conservation International, 24, 354-363.

Donald, P.F., Round, P.D., Aung, T.D.W., Grindley, M., Steinmetz, R., Shwe, N.M. et al. (2015) Social reform and a growing crisis for southern Myanmar's unique forests. Conservation Biology, 29, 1485-1488.

EsRI (2016) How Emerging Hot Spot Analysis Works. pro.arcgis.com/ en/pro-app/latest/tool-reference/space-time-pattern-mining/ learnmoreemerging.htm [accessed 14 June 2021].

FFi (Fauna \& Flora International) (2016) Fauna \& Flora International Calls for Oil Palm Moratorium to Protect Myanmar's Rainforest. Press release. Fauna \& Flora International, Cambridge, UK. fauna-flora.org/news/fauna-flora-international-calls-for-oil- 
palm-moratorium-to-protect-myanmars-rainforest [accessed 14 June 2021].

Gurney's Pitta Working Group (2017) Gurney's Pitta Strategic Plan and 2018 Annual Workplan: Goals and Actions to Protect the Tanintharyi Endemic Gurney's Pitta and its Habitat. Tanintharyi Conservation Programme Report No. 59, Yangon, Myanmar.

Hansen, M.C., Potapov, P.V., Moore, R., Hancher, M., Turubanova, S.A., Tyukavina, A. et al. (2013) High-resolution global maps of 21st-century forest cover change. Science, 342, 850-854

Harris, N.L., Goldman, E., Gabris, C., Nordling, J. Minnemeyer, S., Ansari, S. et al. (2017) Using spatial statistics to identify emerging hot spots of forest loss. Environmental Research Letters, 12, 024012.

Hughes, J.B., Round, P.D. \& Woodruff, D.S. (2003) The Sundaland-Asian faunal transition at the Isthmus of Kra: an analysis of resident forest bird species distributions. Journal of Biogeography, 30, 569-580.

Hume, A.O. (1875) A second list of the birds of Tenasserim. Stray Feathers, 3, 317-326.

Kendall, M.G. \& Gibions, J.D. (1990) Rank Correlation Methods Griffin, London, UK.

Laurance, W.F. \& Arrea, I.B. (2017) Roads to riches or ruin? Science, $358,442-444$.

Laurence, W.F., Sayer, J. \& Cassman, K.G. (2014) Agricultural expansion and its impacts on tropical nature. Trends in Ecology \& Evolution, 29, 107-116.

Lim, C.L., Prescott, G.W., De Alban, J.D., Ziegler, A.D. \& Webb, E.L. (2017) Untangling the proximate causes and underlying drivers of deforestation and forest degradation in Myanmar. Conservation Biology, 31, 1362-172.

Mann, H.B. (1945) Nonparametric tests against trend. Econmetrica, $13,245-259$.
McElreath, R. (2019) Statistical Rethinking, A Bayesian Course with Examples in $R$ and Stan. 2nd edition. Chapman and Hall/CRC, New York, USA.

Namkhan, M., Gale, G.A., Savini, T., Tantipisanuh, N. (2021) Loss and vulnerability of lowland forests in mainland Southeast Asia. Conservation Biology, 35, 206-215.

Ord, K. \& Getis, A. (1995) Local spatial autocorrelation statistics: distributional issues and an application. Geographical Analysis, 27, 286-306.

R Development Core Team (2014) R: A Language and Environmental for Statistical Computing. R Foundation for Statistical Computing, Vienna, Austria.

Round, P.D. (2014) Gurney's pittas in Thailand-from rediscovery to extinction in just 28 years. Natural History Bulletin of the Siam Society, 60, 3-8.

Round, P.D. \& Treesucon, U. (1986) The rediscovery of Gurney's pitta. Forktail, 2, 53-66.

SAXON, E.C. \& ShePpARD, S.M. (2014) Land Suitability for Oil Palm in Southern Myanmar. Working Paper No. 1 of the Fauna \& Flora International, Myanmar Programme, Yangon, Myanmar.

Shwe, N.M., Sukumal, N., Grindley, M. \& Savini, T. (2020) Is Gurney's pitta Hydrornis gurneyi on the brink of extinction? Oryx, 54, 16-22.

Sodhi, N.S., Koh, L.P., Brook, B.W. \& NG, P.K. (2004) Southeast Asian biodiversity: an impending disaster. Trends in Ecology \& Evolution, 19, 654-66o.

USGS (U.S. Geological Survey) (2020) EarthExplorer. earthexplorer.usgs.gov [accessed 9 January 2020].

Wells, D.R. (1976) Resident birds. In The Birds of the Malay Peninsula, Vol. 5. (eds L. Medway \& D.R. Wells), pp. 1-33. Witherby \& Penerbit Universiti Malaya, London, UK and Kuala Lumpur, Malaysia. 